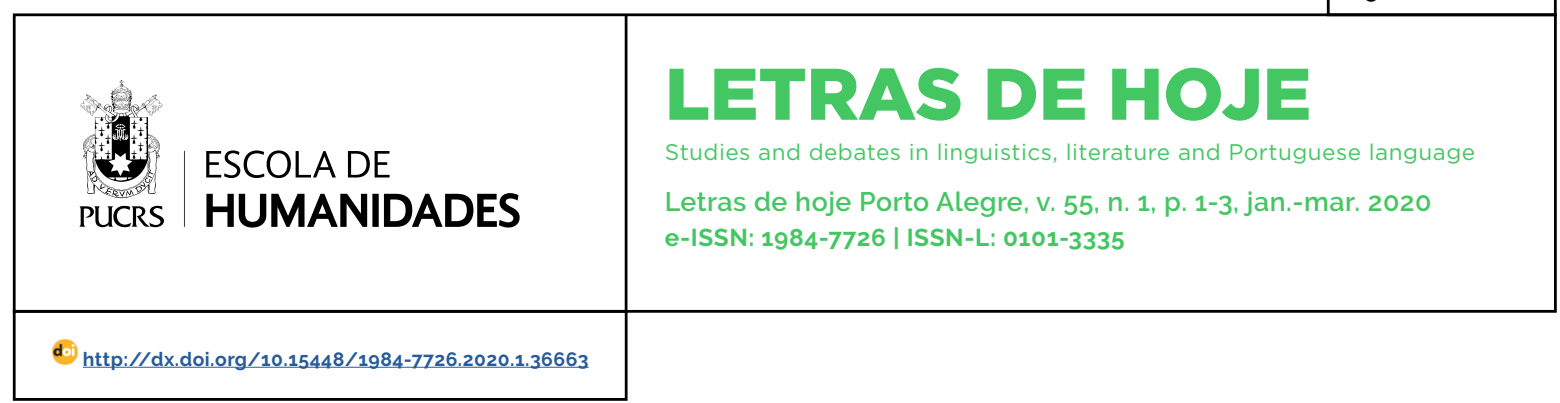

EDITORIAL

\title{
Práticas de intermidialidade
}

Intermediate practices

\section{Practicas intermédias}

\section{Prof. Dr. Antonio Hohlfeldt ${ }^{1}$ \\ orcid.org/0000-0001-5284-8730 \\ a_hohlfeldt@yahoo.com.br}

\section{Profa. Dra. Ana Claudia}

Munari²

orcid.org/0000-0002-6629-588X ana.c.munari@gmail.com

\section{Prof. Dr. Moisés de Lemos Martins ${ }^{3}$ \\ orcid.org/0000-0003-3072-2904 moisesm@ics.uminho.pt}

Prof. Dr. Jorgen Bruhn4 orcid.org/0000-0003-2685-9510 jorgen.bruhn@lnu.se

Recebido em: 16 dez. 2019 Aprovado em: 16 dez. 2019. Publicado em: 14 abr. 2020.

\section{(c) (i)}

Artigo está licenciado sob forma de uma licença Creative Commons Atribuição 4.0 Internacional.
A intermidialidade, como prática, é tão antiga quanto as artes e até mesmo quanto a cultura, se pensamos as primeiras formas de comunicação humana e sua transformação na midiação entre o pensamento e a expressão. Pode-se dizer que a ela está na criação de todo novo modo de se comunicar.

Já os primeiros estudos em Intermidialidade e a construção de uma linguagem própria para pensar e discutir essas práticas entre mídias remontam aos anos 60 do século XX, sobretudo a partir dos anos 80 desse mesmo século, no início da era que Lúcia Santaella convencionou chamar de cultura das midias. É justamente quando as midias se multiplicam, se definem, caem nas mãos de diferentes usuários, ganham novas e diferentes áreas de pesquisa, que os estudos sobre os modos como elas se imiscuem iniciam.

Entre as formas de intermidialidade, a prática trasmidiática é também um procedimento muito antigo, embora se tenha tornado mais comum com o cinema. Ela é a ação de transferir um valor cognitivo, nos termos de Lars Elleström, de uma mídia a outra, o que até pouco tempo somente conheciamos através do termo adaptação. Um conteúdo já midiado é midiado novamente para outra mídia e, para tanto, ocorrem transformações. Nos processos de adaptação, cobrava-se uma certa subserviência à chamada obra segunda, porque, de algum modo, pressupunha-se uma certa hierarquia em relação à obra primeira, muitas vezes também denominada de obra original.

Muitos teóricos da Literatura discutiram estas práticas, sob os mais diferentes aspectos. Lembremos, por exemplo, Mikhail Bakhtin que, logo no início do século XX, entendia que não existe um texto isolado, eis que todos os textos resultam de uma espécie de diálogo entre eles (e dai o termo dialogia, por ele cunhado). Gérard Genette, ao discutir a transtextualidade da literatura, na esteira de Bakhtin, refere-se a esse processo como hipertextualidade, quando um hipotexto dá origem a um hipertexto, este,

\footnotetext{
Pontificia Universidade Católica do Rio Grande do Sul (PUCRS), Porto Alegre, RS, Brasil

Universidade de Santa Cruz do Sul (Unisc), Santa Cruz do Sul, RS, Brasil

Universidade do Minho (UMinho), Braga, Portugal.

Universidade de Linnaeus (LNU), Växjö, Suécia.
} 
uma obra segunda. A paródia, para Genette, é assim um hipertexto, próximo ao que entende, por exemplo, Linda Hutcheon, quando discute as teorias da adaptação, sobretudo aquelas que envolvem a transferência de valores cognitivos da narrativa.

Na prática mais antiga das artes audiovisuais, o Cinema - logo alcunhado como sétima arte, designação que não deixava de reconhecer aquela hierarquia antes mencionada - ao concretizar sua primeira obra de ficção, o fez sob a inspiração da literatura, quando Georges Méliés levou para a tela a narrativa de "Viagem à lua", romance de aventuras de Jules Verne.

O que este dossiê propõe é, justamente, uma reflexão que, partindo da Literatura, pretende pensar as múltiplas, divergentes ou convergentes possibilidades da intermidialidade, seja aquelas que envolvem ajustes entre mídias para pensar o hibrido, seja aquelas que tratem de referências entre mídias, ou até mesmo as transferências, caso da transposição transmidiática ou transmidiação. Os artigos navegam entre produções da própria Literatura, do Cinema, do Teatro, da Arquitetura e da Música, abrindo um largo leque de reflexões extremamente provocativas e produtivas e que, sobretudo, como propõem os estudos em Intermidialidade, as fronteiras entre essas mídias.

Para guiar o leitor através dessas múltiplas propostas, o dossiê se inicia com os textos de Moisés de Lemos Martins - "Tecnologia e literatura - as narrativas transmediáticas" e de Ana Cláudia Munari - "Intermidialidade na literatura brasileira contemporânea" - que servem, ambos, como referenciais teóricos primordiais e, por isso mesmo, colocam-se como dois excelentes textos editoriais para este conjunto. Logo depois, seguimos para a sempre fascinante, mas desafiadora, prática poética, com o artigo de Teresa Jorge Ferreira "A lente incerta da poesia: Herbert Helder e Fernando Lemos"; a literatura ainda é discutida por Alex Martoni, em "Texto, imagem e visualidade na literatura contemporânea brasileira", o que abre uma série de caminhos que começam a mostrar as possibilidades da intermidialidade: Anna Stegh
Camati apresenta uma bela provocação em "Sonho de uma noite de verão: reflexões sobre a ópera de câmara de Benjamin Britten", viajando no tempo e, também, pelas apenas aparentemente distantes linguagens do teatro e da música.

Mas é a televisão e, mais recentemente, os serviços de streaming que ganham a maior atenção dos pesquisadores. Desde o artigo de Alexandre de Assis Monteiro e Luiz Antonio Mousinho - "O modo como expressão do ponto de vista em Dom Casmurro, o romance, e Capitu, a microssérie" - em que títulos de obras e seus personagens verbalizados, cujos pontos de vista parecem ser privilegiados, ganham nossa atenção, atualizando um debate permanente a partir de um de nossos textos mais clássicos; passando por outra figura introjetada em nosso imaginário, graças ao artigo de Camila Augusta Pires de Figueiredo - "In the post-TV era: transmedia and fandom in Shelock, by Moffat and Gatiss" - que também atualiza a figura do célebre Sherlock Holmes.

Brunilda Tempel Reichmann e Anuschka R. Lemos preferem utilizar o termo adaptação, em seu texto, "Adaptação em três atos: Shakespeare, Dobbs e BBC", e podem ser cotejadas com a análise de Rogério Caetano de Almeida e Matheus Gustavo Cavalheiro, em "O insólito em Stardust: análise intermidiática", culminando com "Arquitetura in absentia no conto "Catedral", de Raymond Carver", que Miriam Vieira propõe, e "Transmidiações do poema 'O grande circo místico'", que Antonio Hohlfeldt apresenta, encerrando este dossiê.

O leitor terá, por certo, múltiplos motivos para seguir os textos aqui reunidos, com muito interesse e motivações, graças às suas complexidades e às inovadoras análises propostas.

\section{REFERÊNCIAS}

BAKHTIN, Mikhail. Estética da criação verbal. São Paulo: Martins Fontes, 1992.

ELLESTRÖM, Lars. Midialidade. Ensaios sobre comunicação, semiótica e intermidialidade. Porto Alegre: EDIPUCRS. 2017.

GENETTE, Gérard. Palimpsestos. A literatura de segunda mão. Belo Horizonte: Viva Voz. 2010. 
HUTCHEON. Linda. Poética do pós-modernismo: história, teoria, ficção. Rio de Janeiro: Imago. 1991.

LOPEZ, Manuel Villegas. Cine francês. Buenos Aires: Nova. 1947.

MÉLIES, Georges. Le voyage dans la lune. Paris: Star Film. 1902.

SANTAELLA, Lúcia. Cultura das midias. São Paulo: Experimento. 1992.

\section{Endereço para correspondência:}

Prof. Dr. Antonio Hohlfeldt

Av. Ipiranga, 6681 - Partenon, Porto Alegre - RS, 90619-900

Profa. Dra. Ana Claudia Munari

Av. Independência, 2293 - Universitário, Santa Cruz do Sul - RS, 96815-900

Prof. Dr. Moisés de Lemos Martins

R. da Universidade, 4710-057 Braga, Portugal

Prof. Dr. Jorgen Bruhn

P G Vejdes väg, 35195 Växjö, Suécia 